\title{
Partial Outage, Load Shifting and Solar Based Energy Cost Optimization For Consumers In Developing Countries
}

\author{
Amit Suresh Closepet, \\ Christ University \\ Hosur Road, Bhavani Nagar, \\ Bengaluru, Karnataka 560029
}

\begin{abstract}
To solve the energy crisis in India, it is very important to develop smart algorithms to gain a mush quicker solution to the power cut problems. India, it is filled with a lot of basic essential issues that first needs to be solved such as continuous access for drinking water to all, food for all and most importantly electricity for all. This paper talks about how combining solar energy, load shifting and partial outage can benefit the consumers to tackle the power cut problems. Knowing the power cut scenario in the local areas, the step one of the algorithm calculates, the partial power that can be supplied to the consumers, the second algorithm calculates the loads that can be shifted during the power cuts, the third algorithm calculates how much benefit can be obtained from the solar power that is being generated in the consumer premesis, and finally how much of the back-up i.e. the diesel consumption of the diesel generator can be reduced.
\end{abstract}

Keyword - Load Shifting, Partial Outage, Power Shortage, DSM, Power Management.

\section{INTRODUCTION}

By the end of calendar year 2015, despite poor hydro electricity generation, India has become power surplus country with huge power generation capacity idling for want of electricity demand. The calendar year 2016 started with steep fall in the international price of energy commodities such as coal, diesel oil, naphtha, bunker fuel and LNG which are used in electricity generation in India. Earlier many of the power stations which are using fuels other than coal are unable to operate due to high cost of LNG and petro products. This situation has changed due to glut in petroleum products globally. The prices are falling to such an extent that these fuels have become cheaper to give competition for pit head coal based power generators. Many of the stranded gas and liquid fuel based power stations would be competing with indigenous coal based power stations in an electricity market where demand growth is not encouraging. All the segments of the electricity sector such as fuel suppliers, fuel transporters (railways, harbours, pipelines, etc.), Electricity generators, electricity transmission companies and distribution companies would be facing severe competition to cut down the prices and improve their operating efficiency in a final consumer dictated market. If Discoms, keep on charging exorbitant tariffs to bulk consumers, they would be opting for solar / wind power plants or take over an existing power plant to meet their captive consumption.

\section{Methodology}

(A) Partial Outage Technique: Due to sever power cuts in India, by knowing the schedule of the power cuts well in advance a lot of smartness can be added to the system to manage the power cuts very effectively, using solar, load shifting technique and partial outage techniques. The first algorithm focuses on obtaining a strategic mathematical model using simple computational intelligence designs to efficiently manage the distribution of power to all areas, while also working to maintain grid stability and utility. The second algorithm highlights the methodology to effectively implement PV strategies that would serve to mitigate the effects of a power outage, initially from the perspective of the consumer. Due to recent advancements in technology, evidence is shown that photovoltaic power generation has the potential to overcome these challenges and can lessen the effects of massive power outages. The 3rd Algorithm highlights the load segregation load shifting: Load Segregation \& Categorization : Consumers spend crores of rupees annually only on back-up power. Both diesel as well as inverter-battery as back-up. There is a very crude method of power management in the back-up segment. So it is very important to understand the loads present in the building in order to do fine grain power management on back-up power which is very expensive. 
TABLE 1: Table containing the load profile's of all areas

\begin{tabular}{|c|c|c|c|c|c|c|c|c|c|c|c|c|c|c|c|c|c|c|c|c|c|c|}
\hline \multicolumn{2}{|c|}{ LOAD } & \multirow{2}{*}{$\begin{array}{l}\text { Total } \\
\text { Sanctioned } \\
\text { Load } \\
\text { (kW) }\end{array}$} & \multicolumn{20}{|c|}{ Avg Power Consumption at time $\mathbf{t}(\mathrm{kW})$} \\
\hline $\begin{array}{l}\text { SL } \\
\text { NO }\end{array}$ & AREAS & & 1 & 23 & 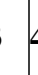 & & & & 8 & s & 11 & & 1 & 13 & & 15 & & $17 \mid 18$ & & 202 & 2122 . & 2324 \\
\hline 1 & AREA 1 & 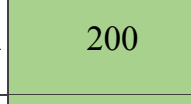 & & $\begin{array}{l}a \\
\dot{a} \\
\dot{a}\end{array}$ & & $m$ & s. & . & & $\dot{\infty}$ & & t. & $\bar{s}$ & $\varepsilon$ & $\begin{array}{l}\overrightarrow{1} \\
2 \\
2 \\
\infty\end{array}$ & $\begin{array}{l}\overrightarrow{0} \\
\overrightarrow{=}\end{array}$ & $\begin{array}{c}0 \\
0 \\
\infty \\
n \\
n\end{array}$ & 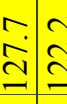 & 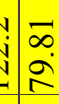 & $\begin{array}{l}\stackrel{1}{R} \\
\stackrel{5}{*}\end{array}$ & $\begin{array}{lll}\infty & 0 \\
0 & 0 \\
& \dot{\infty} \\
\end{array}$ & 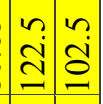 \\
\hline 2 & A 2 & & $\begin{array}{c}\vec{\infty} \\
\infty \\
\infty \\
\dot{\alpha}\end{array}$ & & & & & & & & & $\frac{1}{5}$ & $\delta$ & n? & $\frac{ \pm}{\infty}$ & $\begin{array}{l}\text { f. } \\
\text { ตे. }\end{array}$ & & & $\stackrel{\overbrace{}}{\frac{1}{6}}$ & 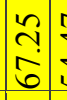 & $\begin{array}{c}\stackrel{y}{+} \\
\dot{v} \\
\stackrel{n}{n}\end{array}$ & 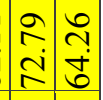 \\
\hline 3 & 3 & & $\begin{array}{l}\infty \\
\infty \\
\dot{0}\end{array}$ & & & & + & & & & $?$ & 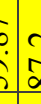 & $\delta$ & $a$ & $\begin{array}{l}\vec{a} \\
\dot{q}\end{array}$ & 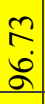 & 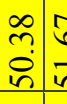 & & $\begin{array}{l}n \\
i \\
\infty \\
\infty \\
\infty \\
n\end{array}$ & $\begin{array}{l}q \\
+ \\
i\end{array}$ & $\begin{array}{ll} \pm \\
\dot{8} \\
i\end{array}$ & 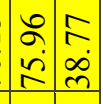 \\
\hline 4 & A 4 & & & & & & & & & & & & & & $\frac{\dot{\sigma}}{n}$ & $\stackrel{n}{n}$ & 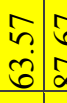 & \begin{tabular}{l|l}
$\hat{b}$ & 8 \\
$\dot{\infty}$ & 8 \\
in
\end{tabular} & $\dot{s} \hat{n}$ & \begin{tabular}{l|l}
$\infty$ & \\
$\dot{f}$ & \\
$\dot{n}$ &
\end{tabular} & 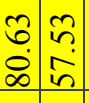 & 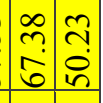 \\
\hline 5 & AREA 5 & 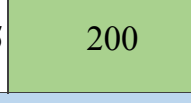 & $\underset{\dot{0}}{\stackrel{+}{=}}$ & $\bar{\sigma}$ & & & & & & & & & & ma & $\stackrel{n}{m}$ & $\stackrel{m}{=}$ & 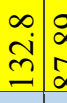 & & 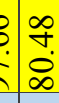 & $\begin{array}{l}\infty \\
\stackrel{\infty}{=} \\
\stackrel{0}{0}\end{array}$ & 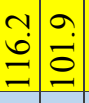 & 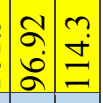 \\
\hline & $\begin{array}{l}\text { cons } \\
\text { ' } t \text { ' }\end{array}$ & & $\mid \begin{array}{l}\vec{\infty} \\
\infty \\
\dot{m}\end{array}$ & & & & & & & & & & & 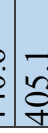 & $\underset{m}{\stackrel{+}{ \pm}}$ & $\begin{array}{l}\vec{\sigma} \\
\vec{\gamma}\end{array}$ & $\begin{array}{l}a \\
\dot{0} \\
m \\
m\end{array}$ & & ‘. & $\left.\begin{array}{c}c \\
\vdots \\
\infty \\
m \\
m\end{array}\right)$ & $\begin{array}{l}\exists \\
\vec{F} \\
\vec{m} \\
\stackrel{i}{m}\end{array}$ & \begin{tabular}{l|l}
$\dot{0}$ & $\overrightarrow{0}$ \\
$\dot{p}$ & $\vec{p}$ \\
$\tilde{m}$
\end{tabular} \\
\hline
\end{tabular}

TABLE 2: Table containing the load profile's of all the users in area 1

\begin{tabular}{|c|c|c|c|c|c|c|c|c|c|c|c|c|c|c|c|c|c|c|c|c|c|c|c|c|c|c|}
\hline SI.No & BUILDINGS & Sanctioned & \multicolumn{24}{|c|}{ Timet $(\mathrm{hr})$} \\
\hline & & Load (kW) & 1 & 2 & 3 & 4 & 5 & 6 & 7 & 8 & 9 & 10 & 11 & 12 & 13 & 14 & 15 & 16 & 17 & 18 & 19 & 20 & 21 & 22 & 23 & 24 \\
\hline 1 & House 1 & 6 & 0.89 & 0.83 & 1 & 0.84 & 0.9 & 0.59 & 1.7 & 3.3 & 5.8 & 5.8 & 1 & 1.8 & 0.74 & 0.7 & 0.8 & 0.5 & 0.52 & 2.49 & 2 & 2.3 & 2 & 2.3 & 0.7 & 0.88 \\
\hline 2 & House 2 & 20 & 2.848 & 2.66 & 3.2 & 2.69 & 2.88 & 1.89 & 5.3 & 10 & 18 & 19 & 3 & 5.8 & 2.37 & 2.3 & 2.6 & 1.7 & 1.66 & 7.97 & 6.4 & 7.36 & 6.4 & 7.36 & 2.24 & 2.82 \\
\hline 3 & Hotel1 & 30 & 10 & 10.2 & 8 & 7.5 & 10 & 8.4 & 8.4 & 10 & 11 & 11 & 11 & 12 & 13 & 15 & 15 & 16 & 8.3 & 9 & 9 & 15 & 16.2 & 18.2 & 18.3 & 13 \\
\hline 4 & House 3 & 10 & 1.068 & 1 & 1.2 & 1.01 & 1.08 & 0.71 & 2 & 3.9 & 6.9 & 6.9 & 1.1 & 2.2 & 0.89 & 0.9 & 1 & 0.6 & 0.62 & 2.99 & 2.4 & 2.76 & 2.4 & 2.76 & 0.84 & 1.06 \\
\hline 5 & Hospital 1 & 20 & 11.4 & 9.39 & 0.24 & 6.74 & 3.24 & 15.9 & 6.2 & 11 & 3.3 & 12 & 5.3 & 13 & 13.8 & 15 & 9 & 1.7 & 4.58 & 18.3 & 3.05 & 16.5 & 10.8 & 19.9 & 1.56 & 8.85 \\
\hline 6 & Mall 2 & 30 & 0.4 & 0.45 & 0.4 & 0.4 & 0.3 & 0.3 & 0 & 0 & 1 & 20 & 19 & 21 & 21 & 21 & 18 & 17 & 17 & 26 & 27 & 27 & 27.5 & 15 & 13 & 6 \\
\hline 7 & House 4 & 10 & 1.36 & 1.26 & 1.52 & 1.28 & 1.37 & 0.90 & 2.54 & 5.00 & 8.76 & 8.82 & 1.45 & 2.77 & 1.13 & 1.10 & 1.22 & 0.81 & 0.79 & 3.79 & 3.05 & 3.50 & 3.05 & 3.50 & 1.07 & 1.34 \\
\hline 8 & School 1 & 30 & 3 & 3 & 3 & 3 & 3 & 1 & 2 & 5 & 10 & 11 & 15 & 20 & 20 & 22 & 20 & 25 & 20 & 7 & 4 & 4 & 3 & 3 & 3 & 3 \\
\hline 9 & Shop 3 & 14 & 0.18 & 0.20 & 0.18 & 0.18 & 0.14 & 0.14 & 0.00 & 0.00 & 0.45 & 9.09 & 8.64 & 9.55 & 9.55 & 9.55 & 8.18 & 7.73 & 7.73 & 11.82 & 12.27 & 12.27 & 12.50 & 6.82 & 5.91 & 2.73 \\
\hline \multirow[t]{2}{*}{10} & Hospital 2 & 30 & 17.1 & 14.1 & 0.36 & 10.1 & 4.86 & 23.9 & 9.3 & 16 & 5 & 18 & 7.9 & 20 & 20.7 & 23 & 14 & 2.5 & 6.87 & 27.5 & 4.575 & 24.8 & 16.2 & 29.9 & 2.34 & 13.3 \\
\hline & & 200 & 48 & 43 & 19 & 34 & 28 & 54 & 38 & 64 & 71 & 121 & 73 & 107 & 103 & 110 & 89 & 74 & 68 & 117 & 74 & 115 & 100 & 109 & 49 & 53 \\
\hline
\end{tabular}

A solved example with general equations is explained below.

' $n$ ' is the number of areas in a given region.

' $t$ ' denote the hourly time variable in a day, i.e., between 0-24 hours.

The power supply available to area ' $\mathrm{n}$ ' at time ' $\mathrm{t}$ ' be $P_{n}^{*}$.

Let the sanctioned load of each area is $S_{n}$

Assume the cost of energy from the grid set by the electricity board is $G_{n}=5$

The total cost of power consumption to be paid by the user for a day (or 24 hours) be ' $C$ '

This algorithm has 2 steps before we have a fare distribution of power.

Considering table 1 area 1 at an hour 9 ,

$\mathrm{t}=9$,

$P_{1}^{\text {P }}=119.4$ 
total power supply required at time ' $\mathrm{t}$ ' by all the areas put together or by a substation is $\boldsymbol{A}^{t}$

From the table 1

$$
A^{9}=411.9 \mathrm{Kw}
$$

Considering a shortage of power supply by $20 \%$ i.e. around $82.38 \mathrm{Kw}$, the net supply available during shortage is $a^{t}$

$$
a^{9}=(411.9-82.38)=329.52 \mathrm{Kw}
$$

This new availibility of power supply is further divided or redistributed based on the sanctioned power $S_{n}$ instead of cutting an individual area's power supply completely the algorithm uses brood force method to tabulate the new power supply available to each area this is represented as $p_{p}^{t}$.

$$
\begin{aligned}
& F_{n}^{*}=\left(a^{*} / A^{*}\right) * P_{n}^{*} . \\
& P_{1}^{p=}=(329.52 / 411.9)^{*} 119.4=95.52
\end{aligned}
$$

Each area is assumed to have 10 establishments as shown in table 2, now the new supply availability of each area has to be further fairly distributed amongst these 10 establishments, for this that same above mentioned algorithm is further broken down and the new supply availability is generated for each establishments.

The MATLAB methodology to model the demand side management optimization and scheduling are described in this section. The MATLAB code is structured in such a manner that it fetches all the input data from various excel files, these excel files can be edited for demand, for the individual load power characteristics, for the load start time, the load run time, for forecasted outage start time \& outage duration etc., Once these inputs are ready we can go to the MATLAB GUI to run the code. Once the code is run for a forecasted outage it results in a new load schedule for the following day depending on the outage. Due to the unreliable grid, we have assumed an error in the outage scenario of maximum of 1 hour on either sides of the forecasted outage. Thus to simulate this unreliable grid we do a real time fuzzy logic based DSM on the loads by creating an error in the outage either in the outage start time or outage end time or even both. Thus depending on the actual outage the fuzzy logic rule base is referred for a further correction in the load schedule to reach to the best optimal cost. The baseline costs assumed for the grid is $5 \mathrm{c} / \mathrm{KWhr}$ (residential) and the baseline diesel costs assumed in the simulation are 20 $\mathrm{c} / \mathrm{KWhr}$. As the power characteristics of the loads are not constant we have divided the day into multiple of a 5 minutes chunk, so 24 hours is considered as 288 chunks, by doing this we can be very accurate in calculating the effective cost, for a better and simple understanding we have assumed all the heavy loads considered in the paper i.e. 3 Geysers, 1 washing machine, 1 dishwasher \& a dryer to have flat power characteristics curves.

(B) Load Shifting Technique:

The cost minimization equation is as follows: Input parameters

LPASSIVE( $\mathrm{t})$ - Passive Load at time $\mathrm{t}$

LSHIFT, $i(t)-$ Shiftable Load $i$ at time $t$

Total Load $\sum(\mathrm{L}(\mathrm{t}))=\sum$ LPASSIVE $(\mathrm{t})+\sum$ LSHIFT, $\mathrm{i}(\mathrm{t})$ for $\mathrm{i}=1, \mathrm{n} \mathrm{tG}$ Grid available time for a day

tB Diesel usage time in a day

$\mathrm{CG}(\mathrm{tG})$ Cost per unit with grid

$\mathrm{CB}(\mathrm{tB})$ Diesel cost per unit

Total cost per unit at time $\mathrm{t} C(\mathrm{t})=\mathrm{CG}(\mathrm{tG})+\mathrm{CB}(\mathrm{tB})$

Total Cost CTOTAL $=\sum \mathrm{C}(\mathrm{t}) \mathrm{L}(\mathrm{t})$ for $\mathrm{t}=0,24$

$\mathrm{COPT}=\operatorname{Min}(\mathrm{CTOTAL})$

Algorithm: - Finding optimal load schedule is done by following the below mentioned flowchart in Figure 2. 


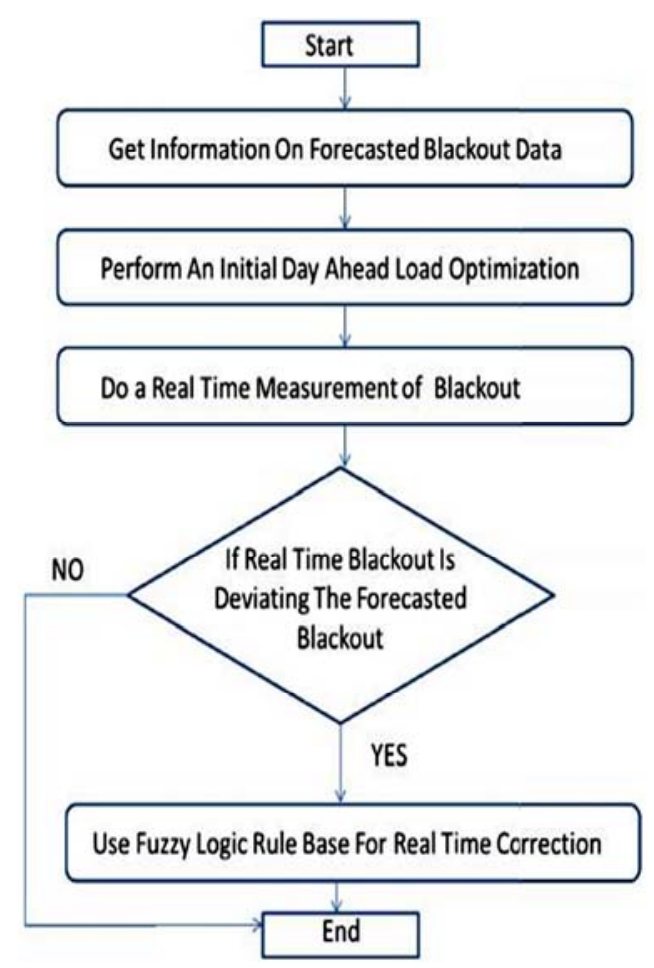

Figure 2: Basic algorithm flow chart

$\mathrm{L}_{\text {NrsT }}$ - Normal Start Time Of Load (1)

$\mathrm{L1}_{N S T}$ - Earliest Start Time Of Load (1)

$\mathrm{L1}_{L S T}$ - Latest Start Time Of Load (1)

$\mathrm{L}_{R T}$ - Run Time Of Load (1)

$\mathrm{L}_{\text {NrET }}$ - Normal End Time Of Load (1)

$\mathrm{L} 1_{N r E T}=\mathrm{L}_{N r S T}+\mathrm{L} 1_{R T}$

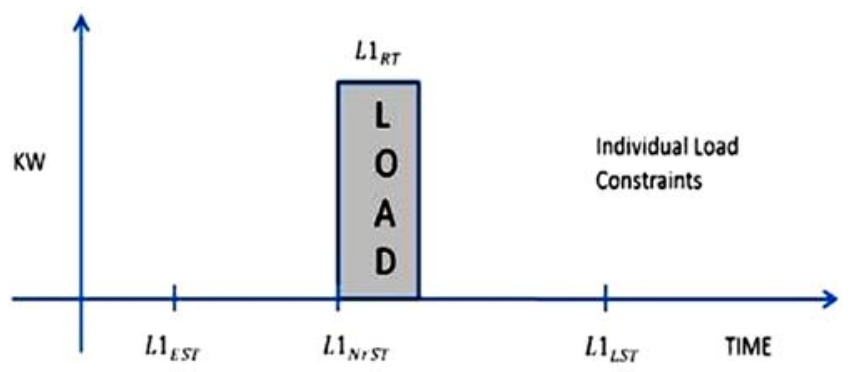

Figure 3. Load schedule constraint

Figure 3 speaks about how every shiftable load is normally scheduled \& also what are its constraints i.e. the load cannot be shifted randomly during the day but has an earliest start limit \& also a latest start limit. Hence any shifting of these loads has to be done between this time frame.

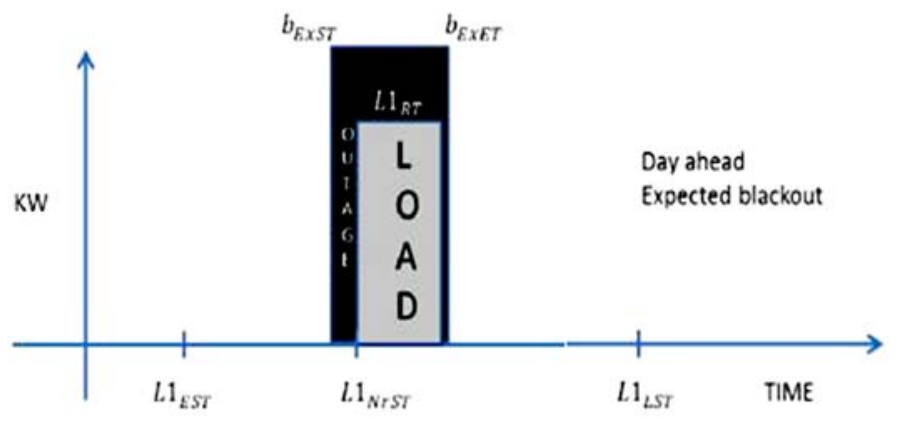

Figure 4. Expected outage for the following day 


\section{$\mathrm{b}_{\text {ExST }}$ - Expected Outage Start Time}

$\mathrm{b}_{\text {ExST }}$ - Expected Outage End Time

In Figure 4 we can clearly observe that the outage is expected to affect the load, thus this load has to be shifted, Thus the load is scheduled to a new start time either before the outage or after the outage, this completely depends on the load constraints \& also the runtime of the load, if the gap is available on both sides of outage, the algorithm chooses to shift the load before the outage as it is safer to execute the load beforehand, rather to risk the execution of the load with the unreliable grid supply. This is seen in Figure 5.

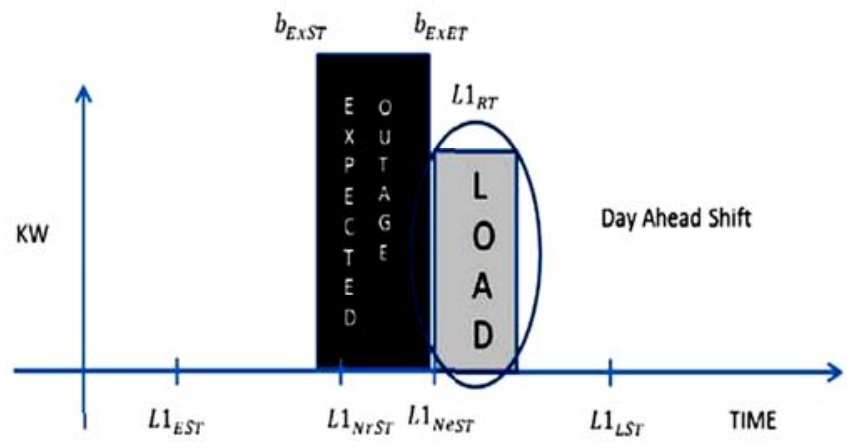

Figure 5 Day ahead Load Shift Schedule

$\mathrm{L}_{\text {NeST }}$ - New Expected Load Start Time

$\mathrm{L}_{\text {NeET }}$ - New Expected Load End Time

$\mathrm{L}_{N e E T}=\mathrm{L}_{N e S T}+\mathrm{L} 1_{R T}$

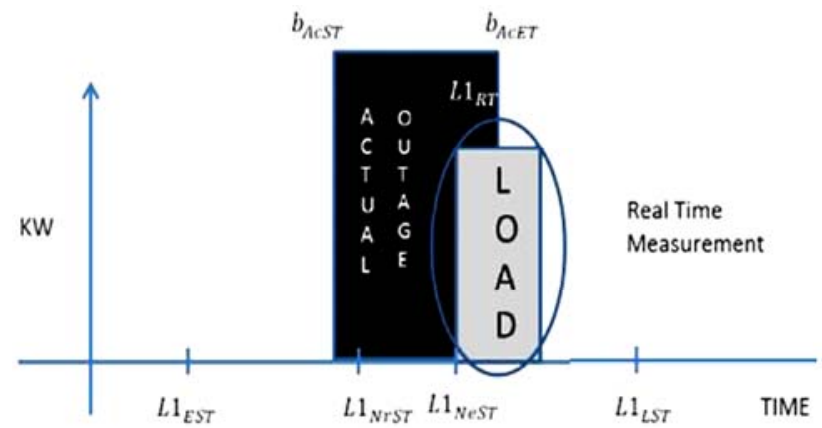

Figure 6. Actual Outage

$\mathrm{b}_{\text {AcST }}$ - Actual Outage Start Time

$\mathrm{b}_{\text {AcET }}$ - Actual Outage End Time

In Figure 6 we can observe that the actual outage is overlapping the new scheduled start time of the load, this data is obtained from the real time supply sensors. Now the real time Fuzzy Logic Rule base for this kind of a scenario where a second shift of the load is required comes into action. The rule mentioned below comes into action $\&$ the load is shifted at the $\mathrm{b}_{\text {ACET }}$ as shown in figure 7.

If $\mathrm{b}_{A C S T} \leq \mathrm{L} 1_{N e S T} \& \mathrm{~L}_{N e S T} \leq \mathrm{b}_{A C E T} \leq \mathrm{L} 1_{N e E T}=>2^{\text {nd }}$ Shift

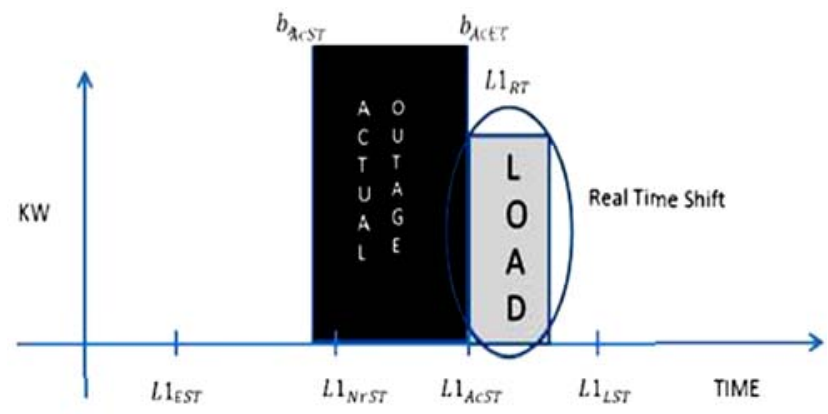

Figure 7. Actual Load Schedule.

L1 $1_{\text {AcST }}$ - Actual Load Start Time

Thus the $\mathrm{L} 1_{A c S T}=\mathrm{b}_{A c E T}$ 
All the shiftable loads undergo this exercise to get the best possible optimal solution to attain the least cost, by finally reaching $\mathrm{COPT}=\mathrm{Min}(\mathrm{CTOTAL})$

Solar based optimization: In this algorithm during a full power condition i.e. during normal condition, the power is being supplied at $100 \%$, suppose there is a shortage of supply the distribution grid implements the algorithm of partial outage as explained in the first algorithm and decides the new power available during the shortage.

Based on this information the other supplies available the $2^{\text {nd }}$ algorithm will implement the load shifting technique as explained above and reduce the requirement of load during the shortage of power supply. Further to this the $3^{\text {rd }}$ algorithm is initiated to further optimize the back up and solar supply available and to deliver to the customer a highly optimized cost of uninterrupted power supply.

In this case the solar capacity installed on the roof top of the consumer is assumed to be equal to the sanctioned load. During normal power supply availability the generated solar power is pumped to the grid and during the scheduled outage the solar power is supplied to the consumer load, hence optimizing the back-up diesel cost.

\section{III.RESULTS}

In this section, the key results and benefits from the MATLAB program for the creation of a partial outage state for both residential and non-residential areas are discussed. For each hour, different cases for load shortage are taken by varying the shortage, based on the shortage percentage (i.e., $20 \%, 40 \%, 60 \%$ and $80 \%$ ).

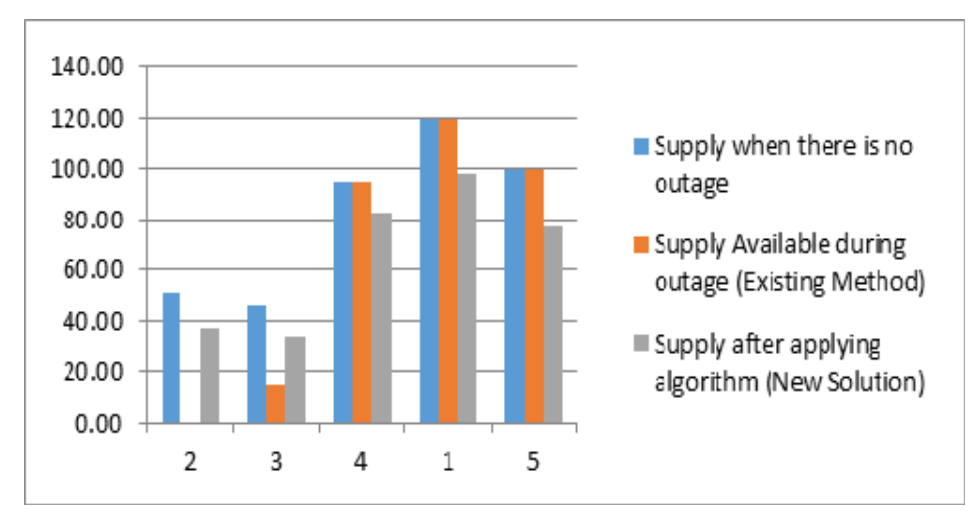

Figure 8: Shows Different Supply patterns for a 20\% shortage of power

TABLE 3: Shows supply distribution for each establishment in an area for $20 \%$ shortage of power

\begin{tabular}{|l|l|l|l|l|l|}
\hline Buildings & $\begin{array}{l}\text { Total } \\
\text { Sanctioned } \\
\text { Load }\end{array}$ & $\begin{array}{l}\text { Actual Supply } \\
\text { when there is } \\
\text { no outage }\end{array}$ & $\begin{array}{l}\text { Supply } \\
\text { available } \\
\text { during an } \\
\text { Outage }\end{array}$ & $\begin{array}{l}\text { Supply } \\
\text { Available after } \\
\text { applying } \\
\text { algorithm }\end{array}$ & $\begin{array}{l}\text { Supply } \\
\text { Deducted after } \\
\text { applying } \\
\text { algorithm }\end{array}$ \\
\hline House 1 & 6 & 5.75 & 0.00 & 3.92 & 1.82 \\
\hline House 3 & 10 & 3.52 & 0.00 & 2.31 & 1.21 \\
\hline House 4 & 10 & 9.03 & 0.00 & 8.03 & 1.00 \\
\hline Shop 3 & 14 & 9.02 & 6.26 & 8.24 & 0.78 \\
\hline House 2 & 20 & 5.54 & 5.54 & 4.74 & 0.80 \\
\hline Hospital 1 & 20 & 3.31 & 3.31 & 2.55 & 0.76 \\
\hline Shop 1 & 30 & 28.79 & 28.79 & 24.80 & 3.99 \\
\hline Shop 2 & 30 & 7.80 & 7.80 & 3.99 & 3.80 \\
\hline School 1 & 30 & 19.47 & 19.47 & 15.89 & 3.58 \\
\hline Hospital 2 & 30 & 27.15 & 27.15 & 23.85 & 3.29 \\
\hline
\end{tabular}

Observing Table 1, Figure 1 and Table 3, area 1 has been considered for this case. The actual load requirement at $9 \mathrm{am}$ is $120 \mathrm{KW}$ for area 1 observe the blue line in figure 1, where as from Figure 1 we observe that there has been $20 \%$ shortage of supply at 9 am for area 1 . In the existing scenario we can observe that area 2 is completely cut off and area 3 is partially cut off observe brown line in Figure 1. After applying the algorithm the green line in Figure 1 shows the redistributed supply finally creating an equilibrium state by not shutting off any areas completely. Now observe Table 3 this explains another step further into the algorithm. Here once the algorithm calculates how much amount of load has to be cut, it has to further cut that load from houses or other establishments, hence referring to Table 3 instead of cutting the supplying to house $1,3 \& 4$ completely, all the establishments in that area get a partial outage. Results of Load Shifting: Considering the load at hour 9 for 
house 1 from table 2, it is observed that the supply required is $5.75 \mathrm{Kwp}$. Out of the $5.75 \mathrm{Kw}$ observe the below table after applying partial outage and load shifting algorithm, we can observe upto $90 \%$ savings at $20 \%$ shortage of supply from table 3 .

TABLE 3: Cost Analysis After applying partial outage and load shifting technique.

\begin{tabular}{|l|l|l|l|}
\hline $\begin{array}{l}\text { Supply } \\
\text { Shortage in \% }\end{array}$ & Supply Required (Watts) & $\begin{array}{l}\text { Partial Supply } \\
\text { (Watts) }\end{array}$ & Shiftable Load (Watts) \\
\hline 20 & 5745 & 3920 & 3500 \\
\hline 40 & 5745 & 2100 & 3500 \\
\hline 60 & 5745 & 280 & 3500 \\
\hline 80 & 5745 & 1690 & 3500 \\
\hline $\begin{array}{l}\text { Supply } \\
\text { Shortage in \% }\end{array}$ & $\begin{array}{l}\text { Cost (Rs) Without Partial } \\
\text { Outage and Load shifting, } \\
\text { Using Diesel Generator }\end{array}$ & $\begin{array}{l}\text { Cost (Rs) After } \\
\text { Partial Outage/ \% } \\
\text { Savings }\end{array}$ & $\begin{array}{l}\text { Cost (Rs) After Partial } \\
\text { Outage and Load } \\
\text { Shifting }\end{array}$ \\
\hline 20 & 114.9 & $56.1 / 51.17$ & $11.225 / 90.23$ \\
\hline 40 & 114.9 & $83.4 / 27.415$ & $13.4 / 88.33$ \\
\hline 60 & 114.9 & $110.7 / 3.655$ & $40.7 / 64.57$ \\
\hline 80 & 114.9 & $89.55 / 22.06$ & $19.55 / 82.98$ \\
\hline
\end{tabular}

Now in table 4 we can observe that for a case 1 i.e. for $20 \%$ shortage of power for area 1 , house 1 observed from table $1 \& 2$ respectively, the savings after the $1^{\text {st }}$ algorithm is around $51 \%$. The savings after applying the $1^{\text {st }}$ and $2^{\text {nd }}$ algorithm is around $90 \%$ and in the $3^{\text {rd }}$ case after applying the $1^{\text {st }}, 2^{\text {nd }}$ and $3^{\text {rd }}$ algorithm the total earnings is around Rs 28/- day.

TABLE 4: Shows the savings in cost by using Solar

\begin{tabular}{|c|c|c|c|c|}
\hline $\begin{array}{c}\text { Supply } \\
\text { Shortage in \% }\end{array}$ & $\begin{array}{c}\text { Supply Required } \\
\text { (Watts) }\end{array}$ & $\begin{array}{c}\text { Partial Supply } \\
\text { (Watts) }\end{array}$ & $\begin{array}{c}\text { Shiftable Load } \\
\text { (Watts) }\end{array}$ & $\begin{array}{c}\text { Solar supply } \\
\text { (Watts) }\end{array}$ \\
\hline 20 & 5745 & 3920 & 3500 & 3027 \\
\hline 40 & 5745 & 2100 & 3500 & 3027 \\
\hline 60 & 5745 & 280 & 3500 & 3027 \\
\hline 80 & 5745 & 1690 & 3500 & 3027 \\
\hline Supply & $\begin{array}{c}\text { Cost (Rs) Without } \\
\text { Partial Outage and } \\
\text { Load shifting, Using } \\
\text { Diesel Generator }\end{array}$ & $\begin{array}{c}\text { Portial Outage/ \% } \\
\text { Savings }\end{array}$ & $\begin{array}{c}\text { Partial Outage and } \\
\text { Load Shifting }\end{array}$ & $\begin{array}{c}\text { Earnings (Rs) after } \\
\text { Partial Outage, } \\
\text { Load Shifting and } \\
\text { Solar }\end{array}$ \\
\hline 20 & 114.9 & $56.1 / 51.17$ & $11.225 / 90.23$ & 28.94 \\
\hline 40 & 114.9 & $83.4 / 27.415$ & $13.4 / 88.33$ & 27.55 \\
\hline 60 & 114.9 & $110.7 / 3.655$ & $40.7 / 64.57$ & 10.15 \\
\hline 80 & 114.9 & $89.55 / 22.06$ & $19.55 / 82.98$ & 23.63 \\
\hline
\end{tabular}

IV.CONCLUSION

Every establishment is different and has its own unique constraints, but the energy supplies are limited. Hence it is very important to choose the right combination of energy sources at right time of the day to achieve the best possible cost optimization possible. The case studies highlight the importance of the algorithms developed, where the customers can benefit greatly from the implementation of the previously mentioned solutions. The study also showed that the actual savings potential depends on the timing of power outage, duration and the specific load characteristics. As diesel prices increase, the economic benefits of these solutions are also increasing correspondingly. Developing countries should consider specific approaches to mitigate power outages and provide relief to customers. Although challenges exist in the implementation of these policies, since most consumers in India and some frugal markets have outdated appliances that are unintelligent with a severe need to develop low- cost smart network-controllable solutions, these policies can improve the consumer's life in terms of cost saving over a longer term and serving green energy. These algorithms can have wide applications in the domestic sector, to help consumers take a decision on installation of solar PV and also for the auxiliary supply in substations. Solar plants can serve as a smarter alternative to the existing fuel based systems and can help reduce the carbon footprint on our planet. 


\section{REFERENCES}

[1] "Basic Research Needs For Solar Energy Utilization Report on the Basic Energy Sciences Workshop on Solar Energy Utilization", April 18-21, 2005

[2] Report, National Centre for Photovoltaic Research and Education (NCPRE) IIT BombaySupported by Ministry of New and Renewable Energy, Govt.Of India

[3] "Jawaharlal Nehru National Solar Mission, Towards Building SOLAR INDIA", Ministry of New and Renewable Energy, India, 2010 http://www.mnre.gov.in/solar-mission/jnnsm/introduction-2/

[4] "Real cost of power" 2009, Universal Consulting

[5] Amit S Closepet, "simple real time non-co-operative game theoretic model for energy cost optimization in developing countries", 2014, APPEEC, Shanghai, China

[6] VenkatNatarajan, Amit S. Closepet, "Statistical Analysis of Cost of Energy Due to Power Outages in Developing Countries", 2012, Future Computing Conf Submission, France

[7] VenkatNatarajan, Amit S. Closepet, "Demand-Side Approaches To Manage Electricity Outages In Developing Countries", 2012, ENERGYCON, Florence, Italy

[8] Amit S. Closepet, "Multi-Layer Optimization For Load Scheduling To Manage UnreliableGrid Outages In Developing Countries" APPEEC Beijing 2013

[9] Amit S. Closepet, K Uma Rao "Simple Power Outage Algorithm For Distribution Network in Developing Countries" IEEE TENCON Singapore November 2016

[10] Amit S. Closepet, "Partial Outage and Load Shifting Based Cost Optimization For Consumers In Developing Countries" IJEE vol 3 